\title{
A STATUTORY VETTING SCHEME FOR THE CHILDREN'S WORKFORCE IN NEW ZEALAND: RIGHTS, RESPONSIBILITIES AND PARAMETERS
}

\author{
Nessa Lynch*
}

New Zealand is unusual amongst comparable jurisdictions in lacking a statutory scheme to vet and possibly disqualify 'risky' individuals from working or volunteering with children. The current vetting process in New Zealand is ad hoc and not transparent. The Government has signalled its intention to place vetting on a statutory footing through the Vulnerable Children Bill. This article considers the appropriate parameters of a vetting scheme, considering the experiences of jurisdictions with established schemes.

\section{INTRODUCTION}

The safety of children is of paramount concern in contemporary society. ${ }^{1}$ High profile cases of harm to children transfix society. In particular, the public (frequently catalysed by a sensationalist media ${ }^{2}$ ) is concerned about the perceived danger of paedophiles and 'sexual predators'. ${ }^{3}$ This is epitomised by the recent furore about the release of Stuart Murray Wilson (the 'Beast of Blenheim'). ${ }^{4}$ Laws that purport to keep children safe are inevitably popular with the public and accordingly appeal strongly to politicians. In furtherance of the mantra of 'keeping our children safe' the prevalence, both nationally and internationally, of measures such as sex offender registration,

* Senior Lecturer, Faculty of Law, Victoria University of Wellington.

$1 \quad R$ (on the application of Wright) $v$ Secretary of State for Health [2009] UKHL 3 per Baroness Hale.

2 Chas Critcher "Media, government and moral panic: The politics of paedophilia in Britain 2000-1" (2002) 3 Journalism Studies 521 .

3 Sean Hier "Thinking beyond moral panic: Risk, responsibility, and the politics of moralization" (2008) 12 Theoretical Criminology 173.

4 "'Beast of Blenheim' to be released" The New Zealand Herald (online ed, Auckland, 17 April 2012). 
sex offender residence restriction rules and vetting schemes has increased. ${ }^{5}$ It is evident that children and those adults who would have contact with them are more under surveillance and control in contemporary society than any time in history.

Those who work with and volunteer with children have considerable responsibility for, and power over, the most vulnerable in our society. In settings such as healthcare, youth work, social work, counselling, education and childcare, the opportunity to do physical, mental or sexual harm to children exists. There are numerous processes by which risk to children can be mitigated. Organisations providing services to children should have a comprehensive child protection plan covering such matters as education, training and supervision. ${ }^{6}$ Education of children themselves is another important facet of child protection. ${ }^{7}$ Nonetheless, given the high level of public concern on the issue, members of the New Zealand public may be startled to find out that individuals with a demonstrable record of harm against children (such as convicted child sex offenders) are not currently automatically prohibited by law from seeking or engaging in work or volunteer activities with children in New Zealand.

This article will discuss statutory or policy measures whereby individuals are subject to checks ('vetted') before they are allowed to work or volunteer with children in an attempt to exclude individuals with relevant criminal convictions or individuals with a history of concerning behaviour from having contact with children. ${ }^{8}$ It is an apt time to reflect on this topic as New Zealand considers the establishment of a more comprehensive vetting scheme as set out in the White Paper on Vulnerable Children..$^{9}$ Legislation - the Vulnerable Children Bill ${ }^{10}$ - creating a 'vetting and screening process' for the children's workforce and certain volunteers passed its First Reading in September 2013 2013, with full implementation by the end of 2017. ${ }^{11}$ The current New Zealand vetting system is ad hoc, not particularly transparent and places the responsibility of assessing risk

5 Jonathan Simon "Managing the monstrous: Sex offenders and the new penology" (1998) 4 Psychology Public Policy and Law 452.

6 Eileen Munro "Learning to reduce risk in child protection" (2010) 40 British Journal of Social Work 1135.

7 Deirdre MacIntyre, and Alan Carr "Prevention of child sexual abuse: Implications of programme evaluation research" (2000) 9 Child Abuse Review 183; Martin Stevens and Jill Manthorpe "Barring 'inappropriate individuals'? The operation of a barring list of social care workers: an analysis of the first referrals to the Protection of Vulnerable Adults list" (2007) 15 Health \& Social Care in the Community 285.

8 Similar schemes exist for those who would work with vulnerable adults. Child protection is the focus of this article.

9 Ministry of Social Development The White Paper for Vulnerable Children Volume 1 (October 2012) at 19.

10 This article was completed before the Vulnerable Children Bill was introduced and passed its First Reading in Parliament. The Bill is sparse on detail and most important details are to be introduced by way of regulation rather than statute.

11 Children's Action Plan "Professionals helping children" <www.childrensactionplan.govt.nz>. 
on the prospective or current employer. Other comparable jurisdictions have gone further and established statutory schemes for both vetting and 'barring' or 'disqualification' (exclusion from employment with children). The issue of the proper parameters of such schemes has come to prominence in recent times, particularly after the introduction, and now partial withdrawal, of the controversial Vetting and Barring Scheme (now referred to as the Disclosure and Barring Scheme) in the United Kingdom. Vetting schemes have been the subject of considerable popular discourse, but there is a distinct lack of analysis in the academic literature (outside the professional journals of the caring professions). ${ }^{12}$ In particular, a consideration that has not been properly addressed is whether and how vetting schemes sufficiently balance individual freedoms with the societal interest of keeping children safe from those who would do harm to them.

Considering both the current vetting process in New Zealand, and examples from jurisdictions employing more extensive schemes, this article will evaluate vetting under a number of headings. First, how can reducing risk to children be balanced against fundamental rights and freedoms such as the presumption of innocence and due process? Secondly, what is the proper role of the state in assessing risk? Should the primary responsibility to assess risk lie with the state, with the employer or with parents? The potential divergence of vetting schemes with the principles of rehabilitation and re-integration of offenders is considered. Lastly, some preliminary conclusions are drawn about an appropriate model of vetting for New Zealand.

\section{VETTING IN NEW ZEALAND}

\section{A Vetting Processes}

Vetting of potential or current employees is a vital component of child protection. While processes such as reference checks and validation of qualifications and experience are important, patently, a criminal record and/or other police record information are important indicators both of past behaviour and of future risk. ${ }^{13}$ As will be discussed in more detail later in this article, jurisdictions differ as to the involvement of the state in the vetting process. Vetting of individuals who would work or work with children does not have a statutory basis in New Zealand. While there are some limited statutory provisions that require police vetting of individuals in particular roles, the form of the vetting process itself is not statutorily prescribed. Nor is the ambit of information which would render an individual unsuitable to work with children. Further, the key principle underpinning the current approach in New Zealand is that risk assessment of prospective or current employees is regarded as being firmly in the realm of the employer. ${ }^{14}$ The prospective employer may, and often

12 See Shereen Hussein and others "Articulating the improvement of care standards: the operation of a barring and vetting scheme in social care" (2009) 38 Journal of Social Policy 1.

13 Shelley A Price and others "Screening procedures in the United Kingdom for positions of trust with children" (2013) 19 Journal of Sexual Aggression 17.

14 In the discussion, the term employer should be taken to include voluntary organisations and the term employee should be taken to include volunteers. 
will, make it a condition of employment (or indeed application for employment) that the prospective employee consents to a vetting process. This may be carried out through two principal means.

First, a criminal records check may be required. The individual must give his or her consent to the obtaining of the criminal record. Police will search the Ministry of Justice database for criminal conviction information. Criminal conviction information released may include the conviction history, date of the offence, the sentence imposed, the location of the court and details of the offence itself. Secondly, the New Zealand Police operate a 'vetting scheme' for authorised organisations. Organisations must be involved in providing services to children or vulnerable adults. ${ }^{15}$ Again, searches of Police or Ministry of Justice information must be authorised in writing by the individual concerned. A person's conviction history will be provided, as detailed above. Traffic infringements are not normally reported unless it involved the suspension of a driver's licence or demerit points. Information on family violence reports may be included. ${ }^{16}$ Non-conviction information, such as matters that did not reach the conviction stage, and details of other involvement, such as being a victim or a witness, may be included. Minimal information will be provided in these situations. The Police may also 'red stamp' the vetting application when an individual's police record indicates behaviour of a violent or sexual nature, and recommend that the individual should not have unsupervised access to children, young individuals (or vulnerable adults). The 'red stamp' process is not a creature of statute, but according to the New Zealand Police: ${ }^{17}$

[T] he basis of a red stamp recommendation is that disclosing the relevant information would breach a Court order or be likely prejudicial to the maintenance of the law, including the prevention, investigation, and detection of offences, and the right to a fair trial. A red stamp recommendation is made, for example, where there is a suppression order in place, or information was provided in confidence, or is in the nature of intelligence.

An official information request to the New Zealand Police yielded the following numbers of 'red stamped' vetting applications in the last five available years. ${ }^{18}$

15 There are approximately 12,000 registered organisations as of January 2013 (Obtained under the Official Information Act 1982 Request to the New Zealand Police by the author).

16 New Zealand Police "What is Police vetting?" <www.police.govt.nz>.

17 New Zealand Police "Red Stamp" <www.police.govt.nz>.

18 Information obtained under the Official Information Act 1982 Request to the New Zealand Police by the author. 
Fig 1: Number of 'red stamped' vetting applications for the last five years

\begin{tabular}{|l|l|}
\hline Date & Volume \\
\hline 2008 & 8 \\
\hline 2009 & 13 \\
\hline 2010 & 22 \\
\hline 2011 & 17 \\
\hline 2012 & 31 \\
\hline
\end{tabular}

No records are kept on how many vetting applications result in the release of information over and above conviction history. ${ }^{19}$ Any information released through a criminal records check or a vetting application is subject to the provisions of the Criminal Records (Clean Slate) Act 2004 (colloquially known as the 'clean slate' legislation). This Act permits individuals to hide certain historic criminal convictions with the aim of promoting reintegration and rehabilitation. ${ }^{20}$ However, the conviction history of individuals may be released despite the provisions of the clean slate legislation where the individual has made an application: ${ }^{21}$

to act in a role predominantly involving the care and protection of, but not predominantly involving the

delivery of education to, a child or young person (for example, a foster parent or a caregiver of children

or young persons).

\section{B Statutory Requirements}

While best practice standards for child protection would hold that every individual who is to have contact with children should be checked and/or vetted, ${ }^{22}$ only certain occupations (generally in the education sector) are statutorily required to subject to the Police vetting process. ${ }^{23}$ Registered teachers and early childhood staff are required by law to be vetted at regular intervals. ${ }^{24}$ Further, individuals who are not registered teachers, holders of a limited authority to teach, or contractors or their employees but are on school grounds during normal school hours must be subject to police vetting before they have unsupervised access to children. ${ }^{25}$ Similar provisions extend to early

19 Information obtained under the Official Information Act, above n 18.

20 Criminal Records (Clean Slate) Act 2004, s 3.

21 Section 19(3).

22 ECPAT "Factsheet 2: Background and Vetting Checks" <www.ecpat.org.nz>.

23 Education Act 1989

24 Section 124B and s 139AZD.

25 Sections 78C-78CC. 
childhood services' staff. ${ }^{26}$ The Health and Safety in Employment Amendment Act 2010 extends a similar provision to limited childcare centres. ${ }^{27}$

In relation to health practitioners, ${ }^{28}$ there is no statutory requirement that a police vetting process be carried out. There are constraints, but no automatic bar where a convicted individual seeks to be registered as a health practitioner. ${ }^{29}$ Section $16(\mathrm{c})$ of the Health Practitioners Competence Assurance Act 2003 provides that an individual cannot be registered as a health practitioner in New Zealand if:

he or she has been convicted by any court in New Zealand or elsewhere of any offence punishable by imprisonment for a term of 3 months or longer, and he or she does not satisfy the responsible authority that, having regard to all the circumstances, including the time that has elapsed since the conviction, the offence does not reflect adversely on his or her fitness to practise as a health practitioner of that profession.

Where a health practitioner is convicted of an offence against certain statutory provisions, ${ }^{30}$ or has been convicted of an offence attracting more than three months imprisonment, the responsible authority must be notified by the Registrar. Some responsible authorities (the bodies responsible for regulating a particular health occupation such as the Midwifery Council of New Zealand or the Social Workers Registration Board) require that an individual be police checked and vetted before he or she is registered. For example, for a qualified individual to use the statutory term 'registered social worker' the individual must register with the Social Workers Registration Board and a condition of registration includes the police vetting process. ${ }^{31}$

Another potential statutory gatekeeping method is the Parole Act 2002. Pursuant to s 14(g) it is a standard release condition that "the offender must not engage, or continue to engage, in any employment or occupation in which the probation officer has directed the offender not to engage or

26 Section 135AA.

27 Sections $13 \mathrm{~A}-13 \mathrm{E}$.

28 Section 5(1) of the Health Practitioners Competence Assurance Act 2003 provides that the term health practitioner or practitioner means a individual who is, or is deemed to be, registered with an authority as a practitioner of a particular health profession.

29 See Leslie v Police HC New Plymouth CRI-2010-443-2, 11 February 2010; and Wafer v Police HC Dunedin CRI-2010-412-1, 11 February 2010.

30 See for example the Births, Deaths, Marriages, and Relationships Registration Act 1995; the Contraception, Sterilisation, and Abortion Act 1977; the Health and Disability Services (Safety) Act 2001; and the Radiation Protection Act 1965.

31 Social Workers Registration Act 2003, ss 6 and 7; and Social Workers Registration Board "New Applicants"<www.swrb.govt.nz>. 
continue to engage". Thus an offender on parole for an offence against children could be directed not to continue or seek employment involving contact with children.

\section{Limitations of the Current Vetting Model}

The effect of statutory requirements and best practice standards should mean that the majority of professionals, employees and volunteers in New Zealand having unsupervised access to children are police checked and vetted. The discussion of the current vetting process demonstrates that vetting is largely non-statutory, and the assessment of the suitability of the individual to work with children is principally regarded as a private matter between the employer and the employee. The prospective or current employer has no direct access to the records of the prospective or current employee. The state does not become involved in assessing suitability or risk (except in providing the conviction history or other information through the vetting process, where the written consent of the individual involved is given).

Further, although the state has prescribed that certain individuals must be vetted by the Police, the statutory requirements are totally silent regarding what the police vet should or should not say. Should the prospective employee have a criminal record, or if other concerning information is released through the vetting process, it is up to the employer to make a decision as to whether to employ the individual. It is not an offence to work with children if one has a conviction history or a 'red stamp' - these are merely tools for the prospective or current employer to assess the suitability of the prospective or current employee. Certain standards for professional registration such as those set out by s 16(c) of the Health Practitioners Competence Assurance Act 2003 require that where an applicant seeking registration has a conviction for an offence attracting a sentence of three months imprisonment or more, the applicant must satisfy the relevant registration body that:

having regard to all the circumstances, including the time that has elapsed since the conviction, the offence does not reflect adversely on his or her fitness to practise as a health practitioner of that profession.

Nonetheless, if an individual with a number of convictions for sexual offences against children was, in the opinion of that particular responsible authority, fit to practise then there is no legal reason why the individual could not engage in employment with children. For individuals outside the ambit of a responsible authority, the employer has full discretion to employ an individual, even if that individual had convictions for serious offending. Further, being non-statutory and operated entirely within the Police, the current model lacks objective and transparent principles, particularly in relation to how the 'red stamp' process operates or when non-conviction information may be released.

\section{STATUTORY VETTING SCHEMES}

In contrast to New Zealand, most comparable jurisdictions (those referred to most regularly here are the jurisdictions of the United Kingdom and Australia) have introduced statutory vetting 
schemes, with considerably wider ambit. The idea of the state being involved in barring 'unsuitable' or 'risky' individuals from working with children is not particularly novel. For example, in California in the 1940s, early forms of sex offender laws banned sex offenders from certain occupations. ${ }^{32}$ The United Kingdom's Secretary of State maintained a list of individuals barred from working with children since the 1920 s and this was statutorily recognised in $2002 .{ }^{33}$

\section{A Converging Contexts}

Comprehensive, systematic and statutory vetting schemes began to be developed in the early 2000s and are reaching full implementation in most Australian jurisdictions and in the jurisdictions of the United Kingdom. While a complete examination of the drivers of child protection legislation is outside the scope of this article, it is evident that the establishment of statutory vetting schemes can be linked both to particular scandals and to a more general moral panic about sex offenders. ${ }^{34}$ The concept of a moral panic was classically defined by Cohen as: ${ }^{35}$

a condition, episode, individual or group of individuals emerges to become defined as a threat to societal interests; its nature is presented in a stylized and stereotyped fashion by the mass media; the moral barricades are manned by editors, bishops, politicians and other right-thinking individuals; socially accredited experts pronounce the diagnoses and solutions; ways of coping are evolved (or more often) resorted to; the condition then disappears, submerges or deteriorates and becomes more visible.

In this particular instance, the public perceives that sexual offending against children is increasing. The public is also disconnected from the evidence of who actually harms children. ${ }^{36} \mathrm{In}$ the United States, the development of restrictive laws mandating registration and restricting residence and employment rights of ex-child sex offenders are strongly linked to a series of high profile cases, particularly 'Megan's Law', a federally mandated sex offender registration scheme. ${ }^{37}$ In this context, the public and policy makers were seen to be "fastening on highly infrequent and

32 Andrew R Hodges "Balancing Evils: State Sex Offender Registration and Notification Laws" (2008) 10 JL Soc'y 134.

33 Nageen Mustafa and others "An Exploration of the Historical Background of Criminal Record Checking in the United Kingdom: From the Eighteenth to the Twenty-First Century" (2013) 19 European Journal on Criminal Policy and Research 15.

34 Hier, above n 3; Kristen M Zgoba "Spin doctors and moral crusaders: The moral panic behind child safety legislation" (2004) 17 Criminal justice studies 385.

35 Stanley Cohen Folk Devils and Moral Panics (3rd ed, Routledge, London, 2001) at 1.

36 James F and others "Societal reaction to sex offenders: A review of the origins and results of the myths surrounding their crimes and treatment amenability" (2004) 25 Deviant Behavior 215; Critcher, above n 2; David Garland "On the concept of moral panic" (2008) 4 Crime, Media, Culture 9.

37 Jill S Levenson and Leo P Cotter "The effect of Megan's Law on sex offender reintegration" (2005) 21 Journal of Contemporary Criminal Justice 49; Jonathan Simon "Megan's law: Crime and democracy in late modern America" (2000) 25 Law \& Social Inquiry 1111. 
particularly heinous acts while studiously overlooking ordinary forms of sexual assault, particularly those committed inside the family that make up the brunt of offences". ${ }^{38}$

In the United Kingdom, the development of a comprehensive statutory vetting scheme can be traced back to the moral panic in 2002 after two English schoolgirls, Holly Wells and Jessica Chapman, were murdered by a school caretaker Ian Huntley. ${ }^{39}$ After Huntley was convicted, ${ }^{40}$ it emerged that he had a long and extensive history of investigation for violence and sexual relationships with underage girls. He had been investigated, interviewed, and even charged on a number of occasions, but he had never been convicted or cautioned. ${ }^{41}$ The public were outraged that someone who had been under investigation in relation to sexual offences could be allowed to work as a school caretaker. ${ }^{42}$ There was also concern about the extent and accuracy of police records; older records had been 'weeded' out and information sharing between the different police districts was poor. ${ }^{43}$ An inquiry was held, and the Bichard inquiry report was published in $2004 .{ }^{44}$ This highlighted the failings of the previous vetting schemes, and was the genesis of the expanded scheme.

\section{B Converging Characteristics}

The principal characteristics of these statutory vetting schemes are broadly similar across jurisdictions. There is an emphasis on the paramountcy of the protection of children. ${ }^{45}$ First, the state may impose a positive duty on an individual who wishes to work or volunteer in child-related activity. ${ }^{46}$ The individual is required to register before seeking or continuing in such activities. Most Australian jurisdictions require that an individual involved in child-related activities is registered

38 Loïc Wacquant "Moralism and Punitive Panopticism: Hunting down sex offenders" in Punishing the poor: The neoliberal government of social insecurity (Duke University Press Books, Durham (NC), 2009) at 21.

39 See generally Nicci Gerrard Soham: A story of our times (Short Books Ltd, London, 2004).

40 His partner Maxine was also convicted as being an accessory after the fact. See Phil J Jones and Claire Wardle "'No emotion, no sympathy': The visual construction of Maxine Carr" (2008) 4 Crime, Media, Culture 53.

41 M Bichard Final Report: An Independent Inquiry arising from the Soham Murders (Home Office (UK), 2004).

42 While noting that he was not the caretaker in the school attended by the victims, but of another school in the village.

43 Paul M Collier "Policing and the intelligent application of knowledge" (2006) 26 Public Money and Management 109.

44 Bichard, above $\mathrm{n} 41$.

45 See Working with Children Act 2005 (Vic), s 1(1); Child Protection (Working with Children) Act 2012 (NSW), s 4

46 Safeguarding Vulnerable Groups Act 2006 (UK). 
and cleared (this is referred to as a 'Blue Card' or 'Working With Children Check'). The definitions of child-related activity vary between jurisdictions, but generally encompass volunteering and paid work and concern direct and/or unsupervised access to children. ${ }^{47}$

Secondly, it is a criminal offence to seek or be in child-related employment if you are not registered, or barred from employment with children. ${ }^{48}$ Thirdly, there are gradations of circumstances in which individuals may be disqualified from employment with children, involving 'autobar' offences (very serious offences where you are automatically disqualified possibly with no opportunity for representation $)^{49}$ or less serious offences where there is automatic disqualification but the individual has the opportunity to make representations to be registered. Fourthly, the remit of information which can be used to exclude an individual may include not only proved instances of offending such as convictions and cautions, but also additional information from police records, prosecution records of dropped charges, and acquittals and 'soft' intelligence. For example, in New South Wales convictions (spent and unspent), charges and juvenile records may be considered as well as notifications of misconduct. ${ }^{50}$

Fifthly, the state may administer an ongoing monitoring function. Rather than a criminal records/history check which provides a snapshot of a particular point in time, the individual may be subject to monitoring until they no longer work with children or are barred from working with children. In New South Wales, holders of a Working With Children Check are monitored for the five year term of the existing check. A risk assessment will be undertaken if concerning information comes to light during that period.

\section{THE APPROPRIATE PARAMETERS OF VETTING}

\section{A Advantages of a Statutory Scheme}

As noted, the New Zealand government has signalled its intention to develop a statutory 'vetting and screening process' for the children's workforce and selected volunteers. The potential

47 For example in New South Wales under s 6 of the Child Protection (Working With Children) Act 2012, child-related work is defined as work in a specific, child-related role or face-to-face contact with children in a child-related sector. In Victoria, the Working with Children Act 2005 provides that 'child-related work' is regular, direct and unsupervised work with children and covers certain occupational categories as defined in the Act.

48 See Working With Children Act 2005 (Vic), s 33; Working With Children (Criminal Record Checking) Act 2004 (WA), s 24

49 See the New South Wales Child Protection (Working With Children) Act 2012, sch 2, which lists the autobar offences. These are generally sexual and violent offences. In Victoria, under the Working with Children Act 2005, certain individuals are disqualified from even applying for a Working With Children Check, notably registered sex offenders, and those who have failed a Check in the last 5 years.

50 Office of the Children's Guardian "New Working with Children Check: What gets checked?" <www.kids.nsw.gov.au>. 
advantages of a more extensive and statutorily-based vetting scheme are clear. The state takes over some responsibility for assessing the risk an individual poses to children, using parameters and factors set out in statute. It is not clear whether the New Zealand government intends to implement a barring or disqualification scheme or to merely place the vetting scheme on a statutory footing and continue to leave the decision to the employer. A state power to disqualify certain individuals from employment or volunteer activities with children does have merit from a child protection perspective. Individuals deemed to pose a very high risk, such as those convicted of sexual or violent crimes, may be automatically excluded from future employment involving children. The concept of automatic disqualification or presumption of disqualification for individuals convicted of certain serious offences such as sexual abuse of children or offences of serious violence would ensure that such individuals would not have unsupervised access to children in the employment or voluntary contexts. Non-conviction information is currently disclosed through the police vetting process, though there are no statutory provisions as to what information may be disclosed. Using more police information (not just information about convictions and cautions) may provide a fuller picture of the individual from which to assess risk. While a criminal records check or a vetting report only provides a snapshot of that individual in time, an on-going monitoring function allows employers to be advised when concerning information about a current employee or volunteer becomes available. Placing the now ad hoc New Zealand Police vetting process on a statutory footing should provide a more transparent and objective process for employers and employees. Protections such as rights of appeal could be set out in the legislation.

\section{B Common-sense Levels?}

Few would argue with the basic concept of a vetting scheme: ensuring that those who have unsupervised access to children in both employment and volunteer contexts have been appropriately assessed and where necessary, disqualified. Constructing the appropriate parameters is more controversial. As to the ambit of such a statutory scheme, the United Kingdom's experience with vetting provides a salutary lesson in reactionary law making. As discussed, the original Vetting and Barring Scheme had an extremely wide ambit and would have meant a large proportion of the adult population (approximately 11 million) would have had to register and be subject to on-going and intrusive monitoring by the state.

While there was undoubtedly public support for the basic concept of vetting, the public's attitude changed rapidly as the potential intrusiveness of the scheme became apparent. In December 2009, Roger Singleton, the former Chief Executive of Barnardo's, was asked by the government to review the Vetting and Barring Scheme with a view to scaling back the scheme considerably, primarily due to public concern. ${ }^{51}$ By 15 June 2010, the new Conservative/Liberal Democrat Government decided to put the partially introduced scheme on hold. The review of the Vetting and Barring Scheme was

51 Roger Singleton 'Drawing the line': a report on the Government's Vetting and Barring Scheme (Independent Safeguarding Authority (UK) 2009). 
released in February 2011. This review recommended that the scheme be essentially scaled back to "common sense" levels, and reduce the proposed group of individuals who need to be vetted from 9 million to 4 million. ${ }^{52}$ The Protection of Freedoms Act 2012 gave effect to many of these recommendations.

What are "common sense" levels? The reforms to the vetting scheme in the United Kingdom involved a number of conceptual changes that should be carefully considered by New Zealand's legislators and policy makers. The first aspect was the narrowing of the definition of individuals who are required to be vetted, by focusing on individuals who have intensive and frequent contact with children. It is now only individuals who pose a serious risk of harm to children who are barred. Otherwise employers have the discretion to make the decision. As the Singleton Report explained: ${ }^{53}$

"Blanket" approaches such as the VBS have the potential to place the emphasis for safeguarding in the wrong place - on the State rather than on employers and individuals. That encourages risk aversion rather than responsible behaviour. And it is the effective management of risk rather than aversion of risk which is most likely to protect vulnerable individuals. That is why we need to redress the balance so that employers are empowered to be able to take proper responsibility for safeguarding with the assistance of a central barring body. After all, it is employers and voluntary groups who are best placed to assess particular risks in their workplace.

Thus, the underlying approach is now that responsibility for safeguarding children lies with many facets of society and not just the state.

The United Kingdom experience also raised questions about how far the state should intervene in the lives of children, with the duties and responsibilities of parents and caregivers, and in the employment relationship. At present in New Zealand, the burden of assessing suitability stands with employers. Using state provided information, prospective or current employers must make an assessment of risk. This may continue to be the best approach, with a state power to disqualify retained for the most serious cases. Further, New Zealand does not intervene in any way with individual arrangements made by a parent or caregiver such as when a parent selects a music teacher for their child, or asks another parent in a sports club to transport their child home. The initial statutory regulations under the United Kingdom scheme would have included any time an individual had contact with a child who was not their own, such as in a carpooling situation where a parent picks up their child's friend to take them to school. This was controversial and would lead to patently ridiculous situations where parents attending a carol service at a school and authors who came to school to read to children would have had to be vetted. ${ }^{54}$ The initial moral panic about harm

\footnotetext{
52 Singleton, above n 51.

53 Singleton, above $\mathrm{n} 51$ at 14 .

54 Singleton, above n 51.
} 
to children gave way to another public outcry when the scheme was thought to be overly intrusive in the lives of parents. These provisions were ultimately reformed so that parents are able to make their own childcare arrangements with other adults, but where parents entrust their children to a school, organisation or club where the parents do not have a choice over who supervises their children, vetting is deemed to be necessary.

\section{The Limitations of Vetting}

In considering the proper ambit of a vetting scheme, the limitations and potential side effects must also be considered. If the objects of vetting schemes are to keep children safe and away from those who would harm them, the first step for legislators and policy makers should be to examine the evidence on how children come to harm. It is perhaps trite to point out that most children are harmed by family members and associates, and vetting is powerless to protect children in these situations.

The concept of vetting feeds into commonly held notions of sexual offenders and particularly child sex offenders. ${ }^{55}$ Society likes to think of offenders generally and child sex offenders more particularly as being somehow outside or different, that we can identify them readily and that they can be removed from contact with society through processes of law. ${ }^{56}$ Nonetheless, the cliché that one is statistically safer in a room full of strangers than you are with your own family rings true in this instance. The very idea of vetting may give parents and children a false sense of security: that if you have been checked then you are somehow 'safe' to work with children. ${ }^{57}$ This is a risky assumption. Vetting schemes, however thorough, are not a replacement for other child protection procedures such as education about healthy relationships and appropriate supervision and training of those who have access to children.

As to potential side effects, it may be that if a more extensive statutory vetting scheme was implemented in New Zealand, volunteers might well be dissuaded from activities involving children, particularly if they would be monitored continuously. ${ }^{58}$

55 Stacey Katz Schiavone and Elizabeth L Jeglic "Public perception of sex offender social policies and the impact on sex offenders" (2009) 53 Int J Offender Ther Comp Criminol 679.

56 Poco D Kernsmith and others "Public attitudes toward sexual offenders and sex offender registration" (2009) 18 Journal of Child Sexual Abuse 290.

57 Anne-Marie McAlinden "Vetting sexual offenders: State over-extension, the punishment deficit and the failure to manage risk" (2010) 19 Social \& Legal Studies 25.

58 Debra Morris "Volunteering: The long arm of the law" (1999) 4 International Journal of Nonprofit and Voluntary Sector Marketing 320; Heather Piper and Ian Stronach Don't Touch!: The Educational Story of a Panic (Routledge, London, 2008); Peter Taylor and others "Child Protection Legislation and Volunteering in Scottish Sport" (2008) 104 Research Digest. 


\section{BALANCING CHILD PROTECTION AND INDIVIDUAL RIGHTS}

The preceding discussion has set out the vetting framework in New Zealand and compared it to more extensive statutory schemes in comparable jurisdictions. This provides a framework for considering the appropriate approach for the proposed New Zealand statutory scheme and dealing with the difficulties in balancing the protection of children from potential harm and abuse with the protection of the fundamental rights and freedoms of the individual.

\section{A A Difficult Balance}

The following two scenarios provide examples of the difficulty in the balancing exercise:

\section{Scenario 1}

$\mathrm{X}$ is convicted of sexually assaulting a teenager when he is 19 years old. He undergoes a community rehabilitation programme and is considered to have a very low risk of re-offending. He does not reoffend and ten years later applies to volunteer as a coach with a teenage girls' soccer team.

\section{Scenario 2}

$\mathrm{Y}$ has had a large number of different charges of sexual assault against different underage girls laid against him. However, none of these have proceeded to trial as in each case the alleged victim decides not to testify and the charges are dropped. He then applies to volunteer with a teenage girls' soccer team.

Instinctively, we would probably consider both individuals to be unsuitable to work closely with children. Nevertheless, the criminal law regards these individuals very differently. Individual X has been convicted of sexual assault. A conviction is societal recognition that an individual has accepted or been attributed responsibility for a forbidden act and is thus able to be sanctioned for the crime. The concept of a criminal conviction is familiar - a standard by which society considers someone guilty of a crime through acceptance or adjudication of criminal responsibility with the protections of due process of law and to the criminal standard of proof. (Some other processes such as diversions and cautions similarly involve the individual freely accepting responsibility for an offence). It is recognised and accepted that consequences other than the initial sanction may flow from convictions, such as visa restrictions and barring from certain employment such as the police or armed forces.

Individual $\mathrm{Y}$ is legally free of responsibility for the alleged offending. He has not been convicted of any crime. The long standing principle of the presumption of innocence provides that individuals are innocent until proven guilty and should not suffer restrictions or sanctions in relation to the alleged offending. But, particularly given the low reporting rate and low conviction rate for sexual offending, should exclusion from working with children or disclosure of information depend only on conviction? What about those individuals, like individual Y, who have a significant history of criminal allegations, but who have not been convicted? 
The power to exclude individuals from employment with children is a powerful one. Patently, employers are free (within the constraints of measures such as anti-discrimination laws) not to employ someone if they receive a poor reference from a previous employer, or are simply regarded as not being a 'good fit' with a particular workplace. However, a statutory vetting regime generally gives the state the power to disqualify individuals from certain positions. This is not just relevant to the particular position that the individual is in or is applying to - it is inclusion on a list of individuals who are barred or disqualified from working with children. This is an extraordinary power and may have significant implications for the barred individual. ${ }^{59}$ First, if you are on the barred list, it may be assumed that you are a paedophile. ${ }^{60}$ But, a much less stigmatising offence could have been relevant. Disqualification from particular employment or volunteer activities is a significant restriction of freedom. It may have a considerable impact on the individual's life.

\section{B Ensuring a Fair Process}

\section{Use of non-conviction information}

As discussed, non-conviction information may currently be reported through the police vetting process in New Zealand and the 'red stamp' process involves the police recommending that the individual should not have unsupervised access to children where the relevant information cannot be reported. There are no statutory guidelines on the use of the 'red stamp' and it essentially involves a judgement of unsuitability on the part of the police. While employers are legally free to employ individuals whose vetting applications have been red stamped, and there is no research in New Zealand on the subject, it is to be assumed that such a declaration would result in the individual's application for employment being denied. Note that the New Zealand Police do not red stamp identities, rather vetting applications. Individuals also have the right under the Privacy Act 1993 to see information held by the Police and to seek to correct such information if necessary, and it is recommended that employers do not act on a 'red stamp' notification without consulting the individual for an explanation. ${ }^{61}$

It is difficult to balance the potential risk to children indicated by non-conviction information and the right of the individual to be considered innocent until proven guilty. However, the current New Zealand system lacks transparency. A new statutory scheme would assist with this by providing clear guidance on when such information may be disclosed or used to disqualify an individual. Statutory vetting models vary in how non-conviction information may be disclosed and/or used to disqualify a person from employment or volunteer activities with children. Under the

59 McAlinden, above n 57.

60 Helen Reece "A complete ban on convicted sex offenders ever looking after children is unfair and unnecessary: it may also leave the government open to legal challenges" (14 December 2010) British Politics and Policy at LSE < http://blogs.lse.ac.uk>

61 New Zealand Police "Results of Vetting" <www.police.govt.nz>. 
New South Wales scheme, if concerning information comes to light (this includes convictions (spent or unspent), charges (heard, unheard or dismissed), juvenile records, findings of misconduct, notifications to the Ombudsman or a pattern of concerning behaviour) a risk assessment is carried out pursuant to s 15 of the Child Protection (Working With Children) Act 2012. This is carried out by the Office of the Children's Guardian and can consider factors relating to the offence, the applicant and the chance of recurrence. In Victoria, checks are made on criminal history and other relevant sources to contribute to the statutory test of risk described below.

Consideration should be given to establishing a statutory test for relevancy of non-conviction information before it can be disclosed to prospective or current employees or used in a disqualification process. Information such as acquittals, where the facts may have been accepted by both parties, or dropped charges where a victim decided not to testify may have more relevance than uncorroborated police information about concerning behaviour. It is evident that statutory prescription of what information can be used would be a much sounder process than the currently ad hoc system which is administered entirely by the Police.

\section{Disqualification}

If New Zealand was to enact a statutory power to disqualify individuals from working with children, the due process rights of individuals must be carefully considered. Care must particularly be taken were an automatic disqualification process to be enacted. Most other comparable jurisdictions have automatic disqualification for certain serious offences such as murder and serious sexual offending. ${ }^{62}$ While this may be justifiable on a child protection basis due to the seriousness of the proved offending, there should be a provision entitling individuals to make representations. That is, the disqualification should not be completely automatic. In the United Kingdom case of Wright, the House of Lords found that aspects of the Vetting and Barring Scheme which placed individuals on the barring list without the right to make representations were contrary to Article 6(1) of the European Convention on Human Rights which provides that "in the determination of his civil rights and obligations...everyone is entitled to a fair and public hearing within a reasonable time by an independent and impartial tribunal established by law." 63 A presumptive disqualification, such as is used in Victoria, would provide a sounder process. Victoria does have an automatic bar for certain offences (such as murder and serious sexual offending), but under Category 2 offences (serious sexual, drug and violent offences) there is a presumption that the individual poses a risk to the safety of children. Registration must be refused unless (considering a number of statutory factors such as

62 Such as Victoria, Queensland, New South Wales and the United Kingdom.

63 Wright, above n 1. 
the circumstances of the offence, the offender and any victim) ${ }^{64}$ a clear statutory test is established. The decision maker must be satisfied that: 65

(a) a reasonable individual would allow his or her child to have direct contact with the applicant that was not directly supervised by another individual while the applicant was engaged in any type of child-related work; and

(b) the applicant's engagement in any type of child-related work would not pose an unjustifiable risk to the safety of children.

This approach, if used for all types of serious offences and with provisions permitting individuals to make representations, is a fairer process than automatic disqualification.

\section{Rehabilitation and Reintegration}

Vetting schemes, whether in relation to the current New Zealand model or the more extensive schemes elsewhere, involve the extension of control of offenders past the judicial and correctional stages. How does vetting fit in with concepts of rehabilitation and reintegration?

Some crimes are so serious (such as sexual violation of a child) that it is proportionate that an individual convicted of these offences should be presumed to pose a risk to children. ${ }^{66}$ That is not to say that the individual should be entirely banned from contact with children, but must be appropriately supervised. New Zealand already has a comprehensive 'clean slate' legislative scheme, which enshrines the principles of rehabilitation and reintegration. Any exceptions to the clean slate legislation that might be contained in a statutory vetting scheme must be clearly justifiable. Historical offending must be treated carefully, even if it is violent or sexual in nature. For instance, individuals who were convicted of indecent behaviour when homosexuality was illegal need to be acknowledged if an automatic barring for sexual offending is introduced. Further, many individuals working in the areas of youth justice, social work and probation are drawn to this work due to their own individual involvement in the criminal justice system. ${ }^{67}$ Consideration of disqualification must be balanced against the potential benefits to society. ${ }^{68}$

64 Working with Children Act 2005 (Vic), s 13(2)(a-h).

65 Section 13(3)(a) and (b).

66 Price, above n 13.

67 Angela Grier and Terry Thomas "The employment of ex-offenders and the UK's new criminal record bureau" (2001) 9 European Journal on Criminal Policy and Research 459.

68 David Wastell and Sue White "Make Kitsch the Enemy: The "Monstrous Carbuncle" of the UK's Vetting and Barring Scheme" in Governance and Sustainability in Information Systems. Managing the Transfer and Diffusion of IT (Springer, Berlin, 2011) 105. 
In considering the disclosure of offences not subject to the clean slate legislation, proportionality must be considered, ensuring that evidence of rehabilitation and the time since the offence are acknowledged ${ }^{69}$ Further, special considerations exist when considering offences committed while the individual was a child or young person. Most offending by children and young persons in New Zealand is disposed of without recourse to prosecution. Orders of the Youth Court made under section 283 of the Children, Young Persons and Their Families Act 1989 are not equal to a criminal conviction, ${ }^{70}$ but can be used when considering sentence in the District Court or High Court. Children and young persons who have been the subject of a section 283 order are entitled to say that they have not been convicted on an offence, but should answer yes in official documents which ask have you ever been charged with an offence or have you ever been before the court in connection with criminal charges. ${ }^{71}$

The law recognises that children and young individuals are less culpable than adults. Except with extremely serious offences (which would be likely to be dealt with through the adult system), different principles govern the disposition of offences and the sanctions imposed. ${ }^{72}$ Very serious offending by children (homicide only) and young individuals (homicide and purely indictable offences) may be dealt with in the adult jurisdiction. Even where the disposition of an offence involves a conviction, special consideration should be given as to whether offences can later be disclosed through a vetting process in order to recognise the lesser culpability of younger offenders.

\section{CONCLUSION}

A process by which individuals posing a serious risk to children are identified and appropriate restrictions placed on their access to children is an important component of child protection. While the basic concept of a vetting scheme undoubtedly has societal support, the appropriate ambit of vetting is a controversial and complicated issue. The New Zealand government has signalled its intention to establish a statutory scheme by introducing the Vulnerable Children Bill. In designing an appropriate statutory vetting scheme for New Zealand, it is vital to first understand the limitations of vetting schemes. Children are much more likely to suffer harm from parents, relatives, caregivers and other children, than non-related adults. ${ }^{73}$ Vetting is also limited in the fact that it only catches those who have acted inappropriately previously, whereas a significant number of those who

69 Shadd Maruna "Who owns resettlement? Towards restorative re-integration" (2006) 4 British Journal of Community Justice 23 .

70 Timo v Police [1996] 1 NZLR 103 (HC).

71 Hartley $v$ State Insurance Ltd HC New Plymouth NP214/98, 11 November 1999.

72 Nessa Lynch Youth Justice in New Zealand (Thomson Reuters, Wellington, 2012).

73 Matthew Colton and others "Learning Lessons from Men Who Have Sexually Abused Children" (2012) 51 The Howard Journal of Criminal Justice 79. 
cause harm to children have no previous convictions or reports of concerning behaviour. ${ }^{74}$ The responsibility to keep children safe is a society wide responsibility, and cannot be totally outsourced to a state agency.

In considering the operation of the proposed statutory scheme in New Zealand, a principled approach must be taken. As noted, the recently published Vulnerable Children Bill has unanimously passed its First Reading. The draft legislation appears to propose a scheme mainly predicated on regulations rather than statute. Protection of children is fundamentally important, but particularly given that vetting is a limited tool, the rights and interests of individuals who are subject to vetting and possible disqualification must also be upheld. Clear and transparent principles on what information can be used must be established, particularly in the limited situations where the use of non-conviction information can be disclosed. There must be appropriate avenues for individuals to query, correct and appeal information and its disclosure. Lastly, any system of disqualification must be proportionate, and take into account the importance of rehabilitation and reintegration of offenders.

74 Colton, above n 73. 
